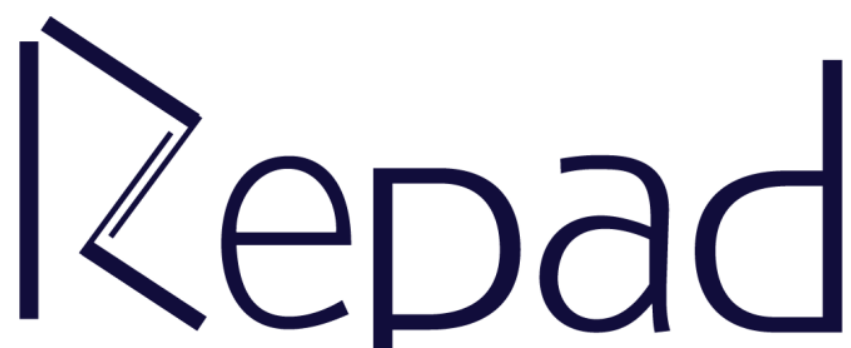

Vol. 2, n. 3, Dezembro/2018

Revista Estudos e

Pesquisas em Administração

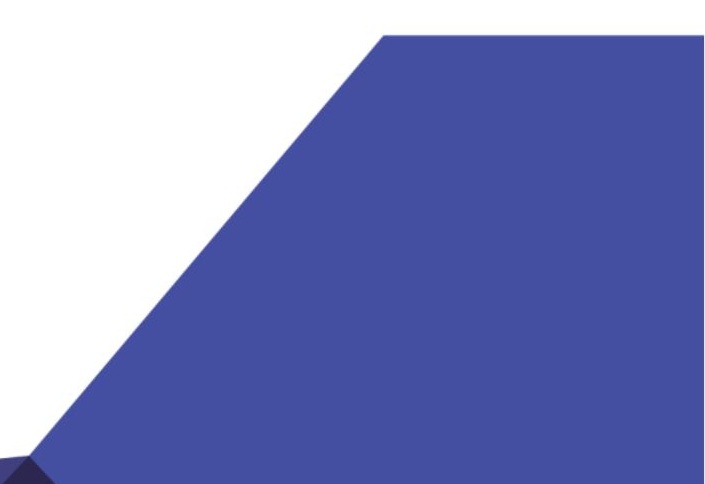




\title{
TECNOLOGIA DE INFORMAÇÃO E AGRICULTURA FAMILIAR: Um estudo de caso em uma pequena propriedade rural em Rondonópolis-MT
}

\author{
Daíla Francielli Assis \\ Universidade Federal de Mato Grosso \\ https://orcid.org/0000-0003-2410-8975 \\ Rodrigo Milano Lucena \\ Universidade Federal de Mato Grosso \\ https://orcid.org/0000-0001-5560-0802
}

\begin{abstract}
RESUMO
Nesta pesquisa objetivou-se verificar se os produtores de uma pequena propriedade rural voltada à agricultura familiar no setor leiteiro de Rondonópolis/MT têm como necessidade a utilização de tecnologias de informação no processo de produção, e dessa forma identificar a importância da utilização da tecnologia como ferramenta auxiliar, proporcionando aos gestores as informações para a tomada de decisão e na contribuição da produtividade. Buscou-se também detectar aspectos relacionados às necessidades do pequeno produtor rural, destacando sua contribuição na formação de renda e na absorção de mão-de-obra. Para tanto, utilizou-se a abordagem metodológica do estudo de caso único na propriedade de produção leiteira, situada na Região do Globo Recreio, com o intuito de identificar suas principais características, a saber, o conhecimento e as necessidades dos produtores em relação às tecnologias, controle de gastos e produção, quais adaptações seriam necessárias para tal investimento, auxiliando consequentemente nas tomadas de decisões, entre outros temas relevantes a pesquisa. Notou-se que os proprietários possuem conhecimento das inovações e que as mesmas podem contribuir e melhorar a produção e o bem-estar, porém existem algumas dificuldades em adotar tais tecnologias. Observou-se que existe um controle parcial da produção e custos, porém não se utiliza de nenhuma ferramenta para sistematizar os processos.
\end{abstract}

Palavras-chave: Agronegócio; Agricultura Familiar; Tecnologia de Informação; Ferramentas Gerenciais; Tomada de Decisão.

INFORMATION TECHNOLOGY AND FAMILY AGRICULTURE: A case study in a small rural property in Rondonópolis-MT

\begin{abstract}
This research aimed to verify if the producers of a small rural property focused on family agriculture in the dairy sector of Rondonópolis/MT have the use of information technologies in the production process as a necessity, and thus identify the importance of the use of technology as a tool, providing managers with information for decision making and contributing to productivity. It was also sought to detect aspects related to the needs of small farmers, highlighting its contribution to the formation of income and the absorption of labor. In order to
\end{abstract}


do so, the methodological approach of the single case study in dairy production, located in the Globo Recreio Region, was used to identify its main characteristics, namely the knowledge and the needs of producers in relation to technologies, control of expenses and production, what adaptations would be necessary for such investment, consequently aiding in decision making, among other topics relevant to research. It was noted that owners have knowledge of the innovations and that they can contribute and improve production and well-being, but there are some difficulties in adopting such technologies. It was observed that there is a partial control of production and costs, but no tool is used to systematize the processes.

Keywords: Agribusiness; Family farming; Information technology; Management Tools; Decision Making

\section{INTRODUÇÃO}

Uma ideia inicial sobre agronegócio é considerar essa atividade ser somente a produção in natura, como por exemplo, grãos e leite, mas o agronegócio é muito mais produtivo e abrangente. Como o nome já diz agrobusiness (agronegócio em inglês), condiz com diversas atividades produtivas que estão ligadas à produção e subprodução de produtos derivados da agricultura e pecuária.

Pode-se entender que o agronegócio é um processo, onde na produção agropecuária intensiva são utilizadas inúmeras tecnologias e biotecnologias para alcançar importantes níveis da produtividade, mas para isso é necessário que a propriedade ou o produtor tenha conhecimento e forneça tais elementos.

A produção agropecuária está diretamente ligada aos alimentos, processados ou não, que fazem parte do nosso cotidiano, porém essa produção é mais complexa, isso porque muitos dos itens que compõe nossa vida são oriundos dessa atividade produtiva, desde madeira dos móveis, as roupas de algodão, essência dos sabonetes até grande parte dos medicamentos têm origem no agronegócio.

Deve-se entender que agronegócio é a soma total das operações de produção e distribuição de suprimentos agrícolas, das operações de produção e armazenamento das unidades agrícolas, e itens produzidos com base neles, englobando fornecedores de bens e serviços e todos os envolvidos até o seu destino final. Nesse complexo também participam os agentes que afetam e coordenam o fluxo dos produtos, sendo o governo, entidades comerciais como mercados, financeiras e serviços. (MENDES; JUNIOR, 2007)

Com relação a agricultura familiar, Segundo Scheneider e Niederle (2010), antes dos anos 90, o termo era pouco utilizado, e os termos utilizados para representar esse grupo era pequeno produtor, produtor de baixa renda e produtor de subsistência. No entanto, após muitas lutas de movimentos sindicais e a criação de políticas públicas, os diversos termos utilizados foram cedendo lugar para o termo atual de agricultura familiar.

Conforme Mendras (1978), o camponês passou de um homem simples, que se dedicava para seu próprio consumo, para o agricultor que articulava várias atividades, inclusive não-agrícolas, onde tinha a necessidade de gerar renda. Segundo CoDAF - Competências Digitais para Agricultura Familiar, atualmente a agricultura familiar tem papel fundamental no abastecimento alimentar brasileiro, onde tem contribuindo para geração de renda, controle da inflação e melhoria no nível de sustentabilidade das atividades agrícolas.

Por mais que a agricultura familiar não possua a mesma visibilidade de uma produção baseada em modelos de grande escala, principalmente as direcionadas à exportação, os empreendimentos familiares possuem a mesma garantia do abastecimento interno alinhado às 
demandas alimentares da população, criando assim um ambiente propício para o desenvolvimento e bem-estar no campo e também a redução da fome.

Para Deponti (2014), com a inclusão de novas tecnologias informacionais, é necessária uma construção conjunta do conhecimento, por meio de capacitações e diálogos, desta maneira, os produtores rurais deverão ter acesso a estas tecnologias e utilizá-las no processo de gestão de sua propriedade. Um exemplo dessa inclusão tecnológica seria, a utilização de planilhas eletrônicas, nas rotinas produtivas das propriedades.

De acordo com Harande (2009), o desenvolvimento produtivo eficaz desse setor só acontecerá se os produtores rurais possuírem acesso à informação significativa e diversificada para as suas atividades. Mais do que isso, é necessário obter a informação e transformá-la em conhecimento, aprender a filtrá-la e processá-la, e identificar a melhor forma de aplicar o conhecimento gerado no campo para ganhos de produtividade e competitividade.

Atualmente, constata-se que o conhecimento dos dados operacionais é essencial para a administração de qualquer empresa. Neste sentido, o sistema de informação gerencial vem para ajudar a análise, o planejamento, a operação e controle da empresa. O sistema de informação gerencial é o sistema responsável pela coleta da maioria dos dados operacionais.

Diante disso, a situação problemática escolhida para desenvolvimento deste trabalho foi em Gestão do Agronegócio e Tecnologia da Informação voltada para a Agricultura Familiar. A pesquisa tem como intuito responder ao seguinte problema de pesquisa: Quais as necessidades e dificuldades dos produtores em relação à tecnologia de informação no processo de produção de uma pequena propriedade rural em Rondonópolis-MT?

A hipótese levantada, de acordo com a literatura prévia sobre o tema, é de que os produtores rurais reconhecem que a tecnologia da informação no campo é fundamental para que seus negócios se tornem mais competitivos. Uma segunda hipótese é a de que mesmo sabendo que a tecnologia da informação é importante, o produtor não possui conhecimento técnico e nem fonte de recursos para acessar novas tecnologias.

A justificativa para tal estudo, está na importância que a tecnologia de informação representa no processo de tomada de decisão dos gestores do agronegócio. Assim, aumentar a eficiência através do uso da tecnologia de informação passa a ser fundamental. Para isso, dois aspectos devem ser analisados: o conhecimento prático do produtor rural e as novas tendências da administração. Estes estabelecem componentes chaves que precisam ser introduzidos ao processo de inovação tecnológica e na busca de um desenvolvimento agrícola sustentável.

Na maioria das vezes a necessidade de tomar decisões em nível crítico de gestão impõem as empresas do agronegócio a coletar e processar grande quantidade de informações, onde as levam a investir em tecnologias da informação. $\mathrm{O}$ mercado oferece uma série de sistemas e ferramentas para manuseio dessas informações. Assim sendo, percebe-se a importância da elaboração de estudos na área, com o intuito de identificar quais as atividades estão efetivamente utilizando a tecnologia da informação na gestão do agronegócio.

Este trabalho tem como justificativa perante a sociedade o fato de trazer identificar possíveis tendências e gargalos para pequeno produtor e seus colaboradores, influenciando na sua produção, evitando possíveis perdas e trazendo possíveis melhorias a pequena propriedade.

A pesquisa irá contribuir com a literatura, pois existem poucas pesquisas relacionadas ao agronegócio e tecnologia da informação voltadas para pequenas propriedades rurais familiares no ramo leiteiro. A pesquisa se justifica também pelo auxílio na ótica do produtor, que poderá ter resultados sobre decisões de investimento e assim obter renda financeira e ganhos de competitividade, ajudando-o a permanecer e conseguir foco no mercado atual. 
Além desta introdução, este trabalho está estruturado com o referencial teórico contendo uma revisão bibliográfica sobre tecnologia da informação e agricultura familiar, seguido dos procedimentos metodológicos, análise dos resultados e por fim as conclusões da pesquisa.

\section{REFERENCIAL TEÓRICO}

\section{TECNOLOGIA DA INFORMAÇÃO}

Para Silva (2002), o termo "tecnologia" tem origem na revolução industrial no final do século XVIII e tem se generalizado para muitas áreas de conhecimento, além dos setores de indústrias e mecânica. Foram utilizadas inúmeras expressões generalizadas, mas nenhuma delas corresponde com "metodologia ou processo", que tem como ponto principal o uso do termo tecnologia para os processos, produtos, equipamentos e operações. Quanto maior o valor tecnológico agregado em uns produtos e/ou processo, maior a capacidade tecnológica da organização que configura esse resultado.

Ferraz e Pinto (2017, pp. 38-49) afirmam que a tecnologia da informação tem como finalidade auxiliar o produtor rural nas tomadas de decisões nos setores da produção. Destacando assim as facilidades decorrentes ao empregar a tecnologia nas etapas da produção agropecuária e na sua gerência contábil, por meio de exemplos de ferramentas. É necessário aplicar a Tecnologia de Informação e Comunicação (TIC) não apenas em métodos manuais, e sim mudar os processos a partir da informatização. Levando em consideração que as ferramentas de TIC não atuam sozinhas, por mais que a informação seja gerada no meio rural, muitas delas são processadas e utilizadas pelo ser humano, tornando necessárias a atuação e a percepção da importância da coleta de informação de maneira correta pelos produtores, técnicos e trabalhadores.

De acordo com Marion e Segatti (2006, pp. 2-7), ao propor um sistema de gestão de planejamento e custos para as pequenas propriedades rurais, estima-se que seu gerenciamento seja de fácil aplicação e manuseio, para ser flexível e calcular qualquer atividade dentro da propriedade rural, de forma integrada ou independente, onde proporciona aos pequenos produtores a possibilidade de conquistar, a médio e longo prazo a sustentabilidade na produção e maior competitividade.

Antonialli e Galan (1997) destacam como os resultados de uma pesquisa realizada em uma propriedade rural no setor leiteiro demonstraram que a adoção de tecnologia pela empresa tem sido implementada dentro da capacidade de investimento de seus recursos próprios. A empresa experimentou uma considerável evolução tecnológica nas seguintes áreas da pecuária leiteira: genética e reprodução do rebanho, instalações, sistema de ordenha, sanidade e nutrição do rebanho, transporte do leite, treinamento dos recursos humanos e assistência técnica. Os esforços em adoção de tecnologia garantiram índices técnicos muitos superiores à média dos produtores mineiros de leite e a proporção de produção atual tem oportunizado custos de produção competitivos. Foi constatada que essa pequena empresa rural se transformou em uma grande produtora de leite e isso só foi possível pela eficiência e competitividade conquistadas no negócio, em função da competência de seus proprietários na gestão de tecnologia. Eles tiveram que escolher entre as várias opções de tecnologia disponíveis no mercado, onde era necessário escolher as mais adequadas à realidade da pecuária leiteira da empresa.

Segundo Santos et al. (2002), as ferramentas gerenciais, que constituem a gestão administrativa de uma propriedade com controles técnicos, são de extrema importância para a competitividade do negócio, pois relevam os indicadores de desempenho e os sistemas de 
manutenção, que garante o sucesso e a sustentabilidade das pequenas empresas rurais, as quais são de vital importância ao grupo agroindustrial do país.

Alguns fundamentos da ciência moderna, dogmática e positivista devem ser interrogados, iniciando pela crença apaixonada de que tecnologia é a porta de saída para todos os problemas, onde se tem a necessidade de se questionar tanto quanto o processo para sua geração e a importância das tecnologias geradas. Podemos destacar, segundo o autor que: "Essa noção crítica escapa aos que assumem a crença apaixonada e unidimensional na deusa moderna: a tecnologia, que é importante, mas não é tudo". (SOUZA, 2009, p.29).

Sousa (2009) identifica um nicho para a geração de tecnologias favoráveis à agricultura familiar, onde existe uma demanda constante de novos consumidores que buscam e exigem produtos de qualidade, com selos de procedência, rastreabilidade, padronização, classificação, sem produtos tóxicos e conservantes, entre outros elementos que demandam por inovação e tecnologias.

Desde a agricultura familiar com o processo produtivo, a adoção da tecnologia pode ser um fator importante para o desenvolvimento da produtividade na propriedade, possibilitando assim ao produtor a facilitação e um melhor desempenho a começar do momento em que este pode moldar melhor às exigências e novidades de suas atividades (CONCEIÇÃO, 2012; SILVA, 2014; SCHWARTZ, 2007).

As novas tecnologias podem ser aplicáveis para facilitar os serviços e a produção que são disponibilizados no meio rural, por exemplo, pode-se analisar o mercado de precificação da produção ou o controle de produção, tornando assim possível verificar a importância de um tipo de produção a ser investido no mercado. Conceição (2012) observou que ainda são poucas as propriedades que utilizam tal mecanismo para o incremento da produção agropecuária.

Mendes, Buainain e Fasiaben (2013) destacam que a Internet é um fator importante na obtenção de vantagem competitiva para auxiliar o produtor em sua propriedade, que pode auxiliar tanto para procurar informações de modo a incrementar a produtividade no domicílio rural, como para buscar novas empresas fornecedoras de insumos, conhecendo sobre novos produtos disponíveis, com a finalidade de melhorar a qualidade e a quantidade da produção.

Com a facilidade ao acesso as tecnologias de informação e comunicação, podem perceber que existem inúmeros benefícios, sendo o maior benefício a eficiência na gestão da propriedade, diminuição de custos e melhora nas tomadas de decisões e assim consequentemente o uso racional dos recursos, aumentando os lucros devido a maior produtividade. Batalha, Buainaim e Souza Filho $(2005$, p.18) afirmam que as possibilidades provenientes com o acesso à internet afirmando que:

A utilização de ferramentas gerenciais aplicadas tanto à gestão de redes de agricultores como às propriedades coloca-se como condição para os agricultores familiares explorarem novas oportunidades que se abririam a partir da formação das redes e da aplicação de tecnologias e práticas que requerem um nível de gestão da produção mais sofisticado.

Pensando na gestão de uma propriedade por meio da visão do agricultor familiar, seu senso econômico é diferenciado. A partir de seu conhecimento a respeito de sua produção, ele consegue antecipar os cenários e assim se ajustar de acordo com necessidades do momento. Conforme Giddens (1991) e Beck (1995), na modernidade reflexiva, há uma transformação nas formas de interação, mediação e comunicação. Consequentemente essas mudanças geram novas formas de ação e interação com o meio, surgindo assim novos olhares sobre delimitados contextos, no caso em análise, a gestão da propriedade. 
De acordo com Costa (2016), é válido dizer que nem toda tecnologia necessita ser complexa para que seja aplicada, e muito menos cara. Também de maneira independente das visões associadas a tecnologia, a inovação precisa manter-se presente no desenvolvimento da tecnologia, visto que somente assim que é possível se obter resultados econômicos satisfatórios.

De acordo com Batalha, Buainaim e Souza Filho (2005), é necessário pensar a utilização da tecnologia no contexto do produto, processo e gestão para que se permita melhorias nas condições de trabalho e desse modo a inserção no mercado por parte das propriedades. Ainda de acordo com os autores a vantagem competitiva advinda da utilização de tecnologias, principalmente as TIC, na agricultura, a tecnologia de gestão necessitaria formar ao lado das tecnologias de produtos e de processos um tripé necessário para a competitividade.

Leeuwis e Ban (2004) destacam que até mesmo nas áreas rurais mais distantes, existem várias conexões diretas ou indiretas com a economia mundial que podem ser consideradas. Com a chegada da "globalização e liberalização do mercado" podemos destacar que seria o cenário em que a Internet se torna um elemento importante na rotina dos agricultores familiares. Além do mais, é necessário destacar que o processo de globalização está atrelado ao acesso aos mercados mundiais que traz oportunidades para a agricultura, diminuindo as barreiras comerciais e a proteção de sistemas agrícolas, o que pode vir a encorajar diversos produtores a se aventurar em novos mercados, até mesmo através da produção de produtos.

De acordo com Mendes e Junior (2007), a evolução da tecnologia na agropecuária foi muito rápida nas últimas décadas, e continua ocorrendo nos dias atuais, provocando alterações estruturais e sujeitando os produtores a frequentes mudanças e adaptações. Os autores ainda ressaltam que nesse contexto que a tecnologia demanda inúmeros investimentos e, de maneira geral, cada tecnologia se adapta de forma diferente de acordo com os tamanhos de atividades econômicas, considerando cada realidade local, seja regional ou cultural, atendendo exigências de consumidores e propriedades.

Righetti e Arns (2016) destacam que muitas vezes, os sistemas de informação e registros agrícolas são confundidos com a realização simples e pura de operações de contabilidade da empresa rural, na qual todas as informações coletadas e armazenadas encontram-se relacionadas aos aspectos contábeis. Os autores ainda destacam que a realidade é que, busca-se uma contribuição de um sistema, onde tem-se a necessidade de um registro sistemático, duradouro e compatível de todas as atividades e operações que ocorrem dentro da propriedade. Assim, além de se buscar o registro das atividades de natureza contábil, esses sistemas buscam efetuar registros relativos a áreas físicas de produção, produtividade ao logo dos anos, informações climáticas, ocorrências adversas, pragas e doenças, indicadores de eficiência de mão de obra, maquinas e equipamentos.

Costa (2016) evidencia a variedade de tecnologias que são utilizadas nos diferentes modelos produtivos. Desde as técnicas mais simples, como as de plantio direto, até as técnicas de maior complexidade, como o caso da utilização de biotecnologia por meio da transgenia, onde seu objetivo é aumentar a produtividade e a eficiências das atividades agropecuárias.

Todo o tipo de tecnologia, possui sua importância e como se trata de um conjunto relativamente numeroso, tem se a necessidade da presença de um profissional que lide com o processo de gestão da adoção das inovações, da mesma maneira que sua gestão operacional, organizando a utilização das mesmas e os recursos indispensáveis para que os trabalhos sejam completamente executados (COSTA, 2006). 


\section{AGRICULTURA E PECUÁRIA FAMILIAR}

De acordo com Hespanhol (2000), até o início da década de 1990, a agricultura familiar era reconhecida como campesinato, pequena produção, agricultura de baixa renda, agricultura de subsistência, entre outras definições. Buainain, Romeiro e Guanziroli (2003) destacam que a agricultura familiar possui um aspecto de diversidade, diferente do campesinato e afirmam que se encontram em universos diferentes, seja em termos de disponibilidade de recursos, acesso ao mercado, capacidade de geração de renda e ampliação.

Sidersky (1990) afirma que utilizando paralelamente os conceitos de pequeno produtor e unidade econômica camponesa, se estabelece três características básicas para definir a unidade econômica camponesa: o acesso aos meios de produção, o caráter familiar da produção e a relação com o mercado.

Entende-se que a agricultura familiar tem prática e características distintas, se comparados à agricultura não familiar. Pois existe a gestão da propriedade que é compartilhada pela família e a atividade produtiva agropecuária é a principal fonte geradora de renda.

Wanderley (1999) considera que o agricultor familiar, até mesmo os completamente inseridos no mercado, ainda são portadores de muitos traços camponeses, pois estão constantemente enfrentando velhos problemas, que nunca tem solução muitas das vezes, e ainda contam com a própria sorte na produção e na comercialização do que produz.

De acordo com Woortmann (1990), os princípios morais da agricultura camponesa apresentam terra, trabalho e família como valores morais intimamente relacionados e tem como princípios a reciprocidade, a hierarquia e a honra. Com fundamento e uma ordem moral de forte inspiração religiosa, que tende a constituir uma ideologia clássica oposta à ordem social da modernidade.

Lima e Figueiredo (2006) apresentam que adotar a expressão de agricultor familiar e não de camponês "pode ter sido uma estratégia, em um momento de transição política, uma vez que o camponês é fundamentalmente uma identidade política e ideológica de sujeitos que através dos anos resistiram e resistem a dominação" (LIMA; FIGUEIREDO, 2006, p. 59).

Em termos conceituais, para que seja mantido o caráter familiar da produção tem-se a necessidade de conter a presença, de ao menos um membro da família, que combine as atividades de administrador da produção com a de trabalhador:

\footnotetext{
A agricultura familiar é aquela em que a gestão, a propriedade e a maior parte do trabalho, vêm de indivíduos que mantêm entre si laços de sangue ou de casamento. Que esta definição não seja unânime e muitas vezes tampouco operacional. É perfeitamente compreensível, já que os diferentes setores sociais e suas representações constroem categorias científicas que servirão a certas finalidades práticas: a definição de agricultura familiar, para fins de atribuição de crédito, pode não ser exatamente a mesma daquela estabelecida com finalidades de quantificação estatística num estudo acadêmico. O importante é que estes três atributos básicos (gestão, propriedade e trabalho familiar) estão presentes em todas elas. (ABRAMOVAY, 1997, p.3)
}

Chayanov (1974) afirma que a empresa capitalista busca o lucro por meio do trabalho assalariado, contudo, a produção familiar tem como prioridade a reprodução da família e a satisfação de suas necessidades. Ainda quando se aumenta o trabalho, pois não se busca lucro, mas sim o bem-estar da família. Ocorre em muitos momentos também a busca pelo lucro, desde que seja direcionado ao interesse da reprodução familiar, diferente da empresa capitalista, que não faz separação entre a gestão e trabalho, lucro e produção.

De acordo com Meira et al. (1996), o incentivo à pequena produção familiar, é como uma linha estratégica para o desenvolvimento rural, onde tem sido o tema principal de muitos 
estudos e reuniões de pessoas interessadas nessa questão e de decisões do atual governo. Muitos estudos, relatam que a agricultura familiar trará muitas vantagens para a sociedade brasileira.

Para Mergarejo Neto (2008), com a diversificação de produção e integração de atividades, foi possível representar para a agricultura familiar uma opção ideal para a dinamização e desenvolvimento de uma agricultura ambiental e socialmente sustentável. Assim, torna-se bastante favorável à junção de práticas sustentáveis pela agricultura familiar, com o cultivo de produtos orgânicos devido a técnica de produção adotado nesse tipo de agricultura.

Conforme ressaltam Oliveira et al. (2008), com o surgimento de uma nova agricultura, vem-se apresentado novas perspectivas para oportunizar a produção, onde se preserva o meio ambiente e, ao mesmo tempo, aponta-se o caminho da sustentabilidade econômica, social e ambiental. Sendo assim, a agricultura orgânica se manifesta como uma possibilidade de uma agricultura sustentável.

Beltrão (2002) destaca a necessidade da diversificação da produção pelos pequenos produtores, expondo a facilidade e a melhor adaptação por esses agricultores aos princípios da agricultura orgânica, sobretudo pela indução do equilíbrio ecológico, reciclagem de nutrientes, insumos, entre outros. Com a utilização de insumos próprios e naturais na cultura acarreta-se também uma diminuição nos custos de produção, transformando-a mais lucrativa ao produtor.

O uso das Tecnologias de Informação por agricultores familiares ainda é muito limitado, pois é preciso avaliar que o cenário em que se tem o acesso a estas tecnologias, inclusive a internet, visto que é escassa ou inexistente. Apesar disso, alguns produtores já utilizam internet e softwares aplicativos, mesmo que não sejam específicos e complexos, tal como, o uso de "planilhas eletrônicas" para sustentar as tarefas cotidianas (ASSAD; PANCETTI, 2009).

\section{PROCEDIMENTOS METODOLÓGICOS}

Para responder ao problema de pesquisa optou-se pela pesquisa qualitativa, utilizandose primeiramente da pesquisa bibliográfica, desenvolvendo-se a partir do material já elaborado por outros autores, ou seja, livros, artigos científicos, teses de dissertação e sites. O trabalho foi estruturado como um estudo de caso único de caráter descritivo.

Segundo Lakatos e Marconi (2001), a pesquisa qualitativa pode ser definida como um estudo não estatístico, que identifica e analisa em profundidade dados de difícil mensuração de um determinado grupo de indivíduos em relação a um problema específico.

Em relação à pesquisa bibliográfica, Vergara (2013, p. 43) afirma que a pesquisa é um estudo desenvolvido com base em livros, revistas, jornais, internet, etc. e fornece material analítico para qualquer outro tipo de pesquisa.

De acordo Gil (2009), o estudo de caso tem o objetivo: explorar situações da vida real cujos limites não estão claramente definidos; preservar o caráter unitário do objeto estudado; descrever a situação do contexto em que está sendo feita uma determinada investigação; formular hipóteses ou desenvolver teorias e explicar as variáveis causais de determinado fenômeno em situações complexas que não permitam o uso de levantamentos e experimentos.

Os dados foram levantados no próprio local, uma chácara de produção de leite situada em Rondonópolis/MT fundada em 2004 e que atualmente produz cerca de 16 mil litros de leite mensalmente.

Para a coleta de dados, aplicou-se um roteiro semiestruturado com questões relacionadas ao agronegócio, agricultura familiar e a tecnologia de informação, as necessidades do pequeno 
produtor relacionado à tecnologia de informação na propriedade rural, entre outros temas relevantes ao assunto pesquisado, aplicadas aos gestores da propriedade rural.

Segundo Minayo (1994), a entrevista privilegia a obtenção de informações através da fala individual, na qual revela condições estruturais, sistemas de valores, normas e símbolos, transmitindo através de um porta-voz, as representações de certos grupos.

$\mathrm{Na}$ análise de dados foram utilizadas as técnicas de análise de conteúdo baseada nos seguintes autores. Segundo Bardin (2009), na pesquisa qualitativa, a análise de conteúdo, o método de organização e de análise dos dados possui algumas características. Primeiro, observa-se que o seu foco seja qualificar as vivências do sujeito, tal como suas percepções sobre determinado objeto e seus fenômenos.

De acordo com Bardin (2009 p. 42), a análise de conteúdo é um conjunto de técnicas de análise das comunicações visando obter, por procedimentos, sistemáticos e objetivos de descrição de conteúdo das mensagens, com indicadores qualitativos ou quantitativos que permitam a interferência de conhecimentos relativos às condições de produção e ou variáveis inferidas das mensagens.

No que se refere à amostragem desta pesquisa, foram entrevistados os dois proprietários de uma propriedade rural que atua no ramo leiteiro na cidade de Rondonópolis. Como é uma propriedade voltada à agricultura familiar realizou duas entrevistas, com o pai Jair Severo Duarte e o filho Andrei Pereira Duarte, onde são os gestores que estão mais envolvidos em todos os processos. Têm idade de vinte e seis a sessenta e dois anos. Quanto à escolaridade, ambos possuem ensino superior completo.

\section{RESULTADOS}

Após a entrevista, iniciou-se uma investigação, e foram analisadas as amostras apresentadas com a finalidade de identificar quando iniciaram e quais motivos os levaram ao ramo da agricultura e se já pensaram em parar em algum momento por alguma dificuldade. No Quadro 1, destaca-se a seguinte pergunta: "Há quantos anos você iniciou no ramo da agricultura?"

\section{Quadro 1: Início na Agricultura}

\begin{tabular}{|c|c|}
\hline E1 & $\begin{array}{c}\text { “...] desde criança eu trabalhei na agricultura }[\ldots] \text { fiquei } 30 \text { anos professor, e voltei pra } \\
\text { agricultura novamente, então praticamente uma vida de agricultura. }\end{array}$ \\
\hline E2 & “[...] aos 10 anos de idade com pecuária de leite $[\ldots]$ ”. \\
\hline
\end{tabular}

Fonte: Elaborado pelos pesquisadores (2018).

Diante da avaliação das respostas dos entrevistados, no Quadro 1 pode-se observar que os dois entrevistados tiveram influência pela família e iniciaram muito cedo no meio da agricultura familiar. De acordo com o Carneiro (1999) apresenta de uma forma sucinta o que a partir de suas análises pode ser considerada por agricultura familiar e acrescenta que parece haver um consenso quando afirma que se pode entender que agricultura familiar, em termos gerais, é uma unidade de produção onde trabalho, terra e família estão intimamente interligadas. 


\section{Quadro 2: Motivos que levaram a atuar no ramo.}

\begin{tabular}{|c|c|}
\hline E1 & $\begin{array}{c}\text { "[...] mais pela necessidade de complementação de salário, e pelo gosto de trabalhar com a } \\
\text { agricultura }[\ldots] \text { então a gente volta [...] e eu acabei sendo agricultor de novo". }\end{array}$ \\
\hline E2 & "[...] por influência do meu pai e do meu tio que já faziam essa atividade". \\
\hline
\end{tabular}

Fonte. Os autores (2018)

Quando questionados sobre "Quais motivos o levaram a atuar no ramo?" Pode-se entender que na agricultura familiar sempre gerações anteriores estão envolvidas com esses tipos de sistema de produção, onde em algum momento as novas gerações tiveram contato com o meio e decidiram por algum motivo continuar no ramo, seja por conta da necessidade de complementação de renda ou por estar dando continuidade ao trabalho da família. Quem atua na agricultura familiar possui um vínculo afetivo, cultural e familiar com a terra e esse tipo de sistema de produção, influenciando sempre na decisão das novas gerações de continuar no ramo.

De acordo com o modo de vida da agricultura familiar, valores, códigos e normas sociais dão sentido à vida social e à condição de ser a própria família a proprietária, a produtora e a gestora da propriedade rural. Assim neste tipo de agricultura, a atividade não é vista apenas na sua dimensão econômica, mas a transcende (ABROMOVAY, 1996).

\section{Quadro 3: Desistir do ramo}

\begin{tabular}{|c|c|}
\hline E1 & $\begin{array}{c}\text { "[...] em vários momentos a gente pensa em parar porque eu acho não existe no Brasil } \\
\text { apoio financeiro e tecnológico para o pequeno produtor. Quando existe, é muito difícil de } \\
\text { você conseguir". }\end{array}$ \\
\hline E2 & $\begin{array}{c}\text { "[...] com a pecuária de leite sim pela enorme dificuldade [...] em questão da mão de obra } \\
\text { e da valorização do produto, mas sair do ramo agrícola não". }\end{array}$ \\
\hline
\end{tabular}
Fonte. Os autores (2018)

Em relação ao Quadro 3 ao perguntar "Em algum momento pensou em parar? Por quê?" Percebe-se que por mais que existam dificuldades no meio da agricultura e tenham o pensamento de desistir em algum momento, ainda não existe a possibilidade de parar com a agricultura, apenas o desejo de mudar o setor. Segundo Rosa Couto (1999), não se pode evidenciar as dificuldades que a agricultura familiar enfrenta: menores indicadores de escolaridade, dificuldade de acesso à energia elétrica e aos meios de comunicação, falta de investimentos em infraestrutura no meio rural, entre outros.

Porém, mesmo com todas essas dificuldades, a agricultura familiar precisa sempre ser fomentada pois, ela é responsável por mais ou menos $70 \%$ da produção de alimentos, é base de 90\% dos municípios brasileiros, em que responde por 35\% do PIB nacional, onde abriga $40 \%$ da população economicamente ativa, mantendo emprego de milhões de brasileiros seja de forma direta ou indireta.

Buscando entender se possuem algum mecanismo tecnológico para realizar o controle da produção e de gastos foi abordado o seguinte questionamento no Quadro 4: "Possui algum mecanismo para realizar o controle de gastos e de produção?”.

Quadro 4: Mecanismo de controle de gastos

\begin{tabular}{|c|c|}
\hline E1 & $\begin{array}{c}\text { "[...] tenho um mecanismo próprio }[. . .] \text { faço um controle por experiência própria, mas } \\
\text { não tenho nada específico, é de tecnologia }[\ldots] " .\end{array}$ \\
\hline $\mathrm{E} 2$ & "Até o momento não". \\
\hline
\end{tabular}

Fonte. Os autores (2018) 
Segundo Fayol (1989, p. 83), "administrar é prever, organizar, coordenar e controlar", ou seja, antecipar o que se deseja fazer, com que recursos e em que quantidades, com a finalidade que os objetivos da empresa sejam alcançados. Desse modo, o conceito é também aplicável à empresa rural. Observa-se nas respostas dos entrevistados, que existe um controle, porem nada preciso e específico. São realizados controles parciais de forma manual. Vale ressaltar que documentalmente, a empresa não encontra pendências jurídicas e nem contábeis, mas o conhecimento prévio dos agricultores nesses respectivos ramos é bem insipiente.

No Quadro 5 foi abordado a seguinte pergunta: "Como é realizado esse controle? E quem o realiza?". De acordo com Maximiano (2006, p. 6) “a administração é o processo de tomar decisões sobre objetivos e utilização de recursos. O processo administrativo abrange cinco tipos de funções: planejamento, organização, liderança, execução e controle". Ainda, Costa (2016) destaca que a variedade de tecnologias que são utilizadas nos diferentes modelos produtivos. Sejam elas técnicas mais simples ou de maiores complexidades.

Quadro 5: Quem realiza o controle

\begin{tabular}{|c|c|}
\hline E1 & $\begin{array}{c}\text { "Eu mesmo realizo o controle [...] é realizado muito parcialmente [...] precisaria muito } \\
\text { mais né”. }\end{array}$ \\
\hline E2 & “[...] é realizado pelo meu próprio pai através de anotações, notas fiscais, e controle \\
diário de produtividade".
\end{tabular}

Fonte. Os autores (2018)

Observa-se nas falas dos autores que tanto no ato, quanto no conceito de administrar pode-se aplicar em qualquer tipo ou forma de organização, independentemente do segmento ou ramo de atuação, baseando nas respostas dos entrevistados, que ainda que existam algumas dificuldades como mão de obra ainda escassa ou falta de conhecimento tecnológico, existe um controle de gastos e produção, porém, tudo de forma manual, sem a ajuda de mecanismos que possam facilitar o dia-a-dia nos processos.

Levando em consideração o conhecimento das ferramentas, foi questionado no Quadro 6: "Você conhece alguma ferramenta/software de gestão?"

Quadro 6: Conhecimento das ferramentas

\begin{tabular}{|c|c|}
\hline E1 & $\begin{array}{l}\text { "Conheço algumas, }[\ldots] \text { muito é superficialmente, a gente tentou implantar }[\ldots] \text { mas não } \\
\text { foi muito a fundo, então precisaria de mais estudos [...] para a gente conseguir chegar". }\end{array}$ \\
\hline E2 & "[...] somente Excel para planilhas". \\
\hline \multicolumn{2}{c}{ Fonte. Os autores (2018) }
\end{tabular}

Diante da avaliação dos entrevistados, percebe-se que existe conhecimento das ferramentas de gestão, porém ressaltam que tudo de forma superficial, e entendem que necessitam de um conhecimento mais afundo para realizar a implantação das mesmas. Além disso, um dos entrevistados afirma que já tentou implantar um software de gestão da informação e produtividade, que por falta de recursos financeiros e de treinamento, não foi mais utilizado.

Ainda com o intuito de saber mais sobre como ficaram sabendo da existência dessas ferramentas foi questionado no Quadro 7: "Como ficou sabendo da existência dessa ferramenta?". 


\section{Quadro 7: Existência das ferramentas}

\begin{tabular}{|c|c|}
\hline E1 & "[...] através de pesquisas da internet, conversas [...]". \\
\hline E2 & “[...] através de cursos de computação. E do programa de controle do leite através do meu primo". \\
\hline
\end{tabular}

Fonte. Os autores (2018)

De acordo com as respostas obtidas, percebeu-se que existe um conhecimento das ferramentas através de pesquisas na internet, cursos de computação e conversas. E foi relatado que existiu um projeto para implantação de uma ferramenta para controle de custos e produção, porém houve a dificuldade para a implantação na questão de custos e mão de obra. Enfatiza-se aqui que os produtores não possuem contato com universidades, centros de pesquisa, associações ou até mesmo o sistema $\mathrm{S}$, que poderia estreitar a ponte entre o conhecimento tecnológico e as suas necessidades.

Para dar mais firmeza a percepção do conhecimento, foi abordada a seguinte pergunta no Quadro 8: “Já participou de feiras agropecuárias e/ou eventos relacionados?".

Quadro 8: Participação em eventos agropecuários.

\begin{tabular}{|c|c|}
\hline E1 & $\begin{array}{c}\text { "[...] participei da feira agropecuária aqui em Rondonópolis, já estivemos vaca na } \\
\text { exposição por exemplo [...]". }\end{array}$ \\
\hline E2 & "Sim, $[\ldots]$ de feiras agropecuárias". \\
\hline
\end{tabular}

Fonte. Os autores (2018)

Baseando-se nas respostas dos entrevistados, existe um esforço considerável, embora não suficiente de desenvolvimento de tecnologias voltadas para os agricultores familiares. Araújo (2003) destaca que a maioria das propriedades do segmento agrícola não possuem técnicas de gestão devido à falta de qualificação formal. Quando estas propriedades passam a utilizar de sistemas de informação gerencial, elas se veem obrigadas a se reorganizarem para se adequar. $\mathrm{O}$ autor ainda destaca as dificuldades encontradas pelos produtores para a utilização e informatização desses novos sistemas.

Os cenários evolutivos da economia representam um avanço na forma de gerir a propriedade rural, com isso, o empresário deve buscar novas ferramentas que lhe propiciem resultados práticos, rápidos e com alto teor de assertividade (ARAÚJO, 2003).

Segundo Castells (2003), geralmente no meio rural, o acesso à informação e a tecnologias se torna mais complicado por condições geográficas, mas nos últimos anos o campo vem se incluindo digitalmente e inserindo a tecnologia no dia a dia do trabalho e da família. $\mathrm{O}$ autor ainda afirma que "internet não é simplesmente uma tecnologia: é um meio de comunicação" (CASTELLS, 2003, p. 116).

De acordo com Batalha, Buainain e Souza Filho (2004), o baixo nível tecnológico dos agricultores familiares não pode ser explicado apenas pela ausência de tecnologia adequada, mas pelo contrário, em muitos casos, mesmo com a tecnologia disponível, a mesma não se transforma em inovação devido à falta de capacidade e condições para se atualizar.

Por mais que os entrevistados responderam participar de feiras agropecuárias, este fato torna insuficiente para a gestão correta do negócio. Seria necessário muito mais do que "conhecer" ou "já ouvi falar" de tecnologias modernas disponíveis para seus negócios. A busca pelo conhecimento e pela inovação deve ser efetiva, constante e duradoura dentro da organização. 
De acordo com as falas dos entrevistados no Quadro 9, quando perguntado: "Hoje qual a maior necessidade da propriedade em relação a tecnologias de informações (maquinário, programa/software/ferramenta, tratores, etc.)?”, percebe-se que os produtores necessitariam de investimento em maquinários mais tecnológicos, ferramentas de controle de produção e custos, todo o tipo de tecnologia, porém o investimento ainda é alto. E por mais que existam incentivos do Governo na área da agricultura familiar, eles se sentem para escanteio, e muitas vezes para conseguir tal investimento é muito burocrático, dificultando o acesso e a melhoria.

Batalha, Buainain e Souza Filho (2004) relatam que o baixo nível tecnológico dos agricultores familiares brasileiros não pode ser explicado apenas pela falta de tecnologia adequada; pelo contrário, em muitos casos, mesmo com a tecnologia disponível, ela não se transforma em inovação devido à falta de habilidades e condições para inovar. $\mathrm{O}$ reconhecimento de que o desempenho e a disponibilidade dos agricultores dependem de um conjunto de fatores e agentes que constituem um sistema, mais ou menos integrado ou harmônico, conduz a análise para a cadeia agroindustrial e solicita um enfoque sistêmico.

\section{Quadro 9: Necessidade da propriedade}

\begin{tabular}{|c|c|c|}
\hline E1 & $\begin{array}{c}\text { "Programas tecnológicos, tudo, né, minha maquinas já são obsoletas [...] eu precisaria de } \\
\text { tratores diferenciados, maquinas diferenciadas, só que hoje é muito complicado você } \\
\text { conseguir financiamento pra você conseguir montar isso, porque a gente se considera } \\
\text { uma agricultura familiar [...] pouco investimento do Governo nesta área [...] deveria } \\
\text { investir muito mais [...] estamos ainda meio pra escanteio." }\end{array}$ \\
\hline E2 & $\begin{array}{c}\text { "Toda tecnologia [...] de baixo custo e que forneça um controle e uma produtividade } \\
\text { maior é [...] bem-vinda, mas [...] os maiores problemas são na parte de gestão de dados e e } \\
\text { uma mecanização maior da mão de obra pra dependermos cada dia menos de pessoas". }\end{array}$ \\
\hline
\end{tabular}

Fonte. Os autores (2018)

Levando em consideração as necessidades em adotar tais tecnologias, foi questionado ainda sobre as dificuldades para adotar tais tecnologias, foi questionado no Quadro 10: "Quais as maiores dificuldades em adotar um programa/software/ferramenta que auxilie nessa gestão?". Diante dos relatos obtidos pelos entrevistados, percebeu-se que a falta de conhecimento é a maior dificuldade, pois além de necessitarem de um alto investimento, a falta de conhecimento da ferramenta é o que mais prejudica.

Rossine e Palmisano (2008, p.101) destacam que "A tecnologia de informação é um agente facilitador muito importante em qualquer mudança que haja numa organização, principalmente naquelas em que os processos e trabalhos eram realizados de forma manual ou artesanal".

\section{Quadro 10: Dificuldades em adotar}

\begin{tabular}{|c|c|}
\hline E1 & $\begin{array}{c}\text { "[...] falta muito conhecimento [...], por exemplo, eu preciso de me informar mais e isso } \\
\text { me prejudica muito }[\ldots] \text { falta de tempo pra você fazer cursos [...] ter pessoas } \\
\text { especializadas [...]". }\end{array}$ \\
\hline E2 & $\begin{array}{r}\text { "[...] somente a complexidade do mesmo. Tanto na questão de acesso quanto na questão } \\
\text { de lançamento de dados no programa. [...] às vezes que teria que fazer esse tipo de } \\
\text { lançamento teria poucas instruções para isso". }\end{array}$ \\
\hline
\end{tabular}

Fonte. Os autores (2018)

Quando perguntado "Em vista das dificuldades em adotar um programa/software/ferramenta, quais as melhorias que o senhor (a) acha necessário realizar dentro da sua propriedade para facilitar seu trabalho?", as respostas foram as do Quadro 11. 
Quadro 11: Melhorias dentro da propriedade.

\begin{tabular}{|c|c|c|}
\hline E1 & $\begin{array}{c}\text { "...] teria que implantar internet [...] ter computador [...] fazer, manipular os programas } \\
{[\ldots] \text { falta um monte de coisa [...] nós estamos engatinhando ainda em relação a isso". }}\end{array}$ \\
\hline & $\begin{array}{c}\text { "Um controle maior de custos de produção. Saber [...] o que se gasta por litro de leite } \\
\text { produzido, para sabermos quanto que a propriedade tem que produzir para pagar as } \\
\text { E2 }\end{array}$ \\
& $\begin{array}{c}\text { Entas. [...] melhorias em estrutura como curral para um melhor bem-estar de animal e } \\
\text { funcionários". }\end{array}$
\end{tabular}

Fonte. Os autores (2018)

De acordo com as respostas dos entrevistados, notou-se que a propriedade necessita de muitas melhorias em questão de equipamentos para facilitar o uso das tecnologias, implantar internet para facilitar o acesso à ferramenta, entre outras melhorias.

Caleman (2015) destaca que o agronegócio tem se desenvolvido e se adaptado a um ambiente mais globalizado, complexo e competitivo. Assim, é necessário se adaptar as novas tendências do mercado agroindustrial, para se obter mais eficiência e produtividade. Um exemplo simples, para que o alimento orgânico chegue até o consumidor final, é necessário que o produtor adeque sua propriedade para esse tipo de produção.

Em vista das melhorias, foi questionado no Quadro 12 sobre: "Quais adaptações são necessárias nas ferramentas de gestão disponíveis para que elas possam ser usadas adequadamente pela agricultura familiar?".

Quadro 12: Adaptações

\begin{tabular}{|c|c|}
\hline E1 & $\begin{array}{c}\text { "Eu conheço poucas }[. . .] \text { então as que eu conheço }[. . .] \text { falta à gente discutir mais, } \\
\text { aprofundar mais". }\end{array}$ \\
\hline E2 & $\begin{array}{l}\text { "[...] captação maior de dados e uma das maiores adaptações seria }[\ldots] \text { treinamento para } \\
\text { os usuários finais desse produto, pois }[\ldots] \text { esse é o maior defeito, não saber usar". }\end{array}$ \\
\hline
\end{tabular}

Fonte. Os autores (2018)

Diante da avaliação das respostas dos entrevistados, destacou-se que existe certa dificuldade em relação à implantação, pois ainda não possuem conhecimento específico para tal mecanismo. Destacou-se também que existe a necessidade de uma maior captação de dados e treinamentos para os usuários finais, e a falta de mão de obra capacitada no meio rural se tornam um obstáculo para implantar as tecnologias necessárias.

Dessa forma, observamos nas respostas dos entrevistados quando perguntado no Quadro 13: "Quais mecanismos podem ser utilizados para que sejam estimulados a utilizarem estas ferramentas?", que as maiores dificuldades encontradas no meio de produção é a falta de mecanismos que os auxiliem na produção e controle, como mais cursos de informação para o pequeno produtor, treinamentos, entre outros tipos de mecanismos para um uso mais consciente e preciso das ferramentas a ser adotadas.

\section{Quadro 13: Mecanismos a ser utilizados}

\begin{tabular}{|c|c|}
\hline E1 & "Mais cursos de informação para o pequeno agricultor, chegar mais informação [...]". \\
\hline E2 & "[...] treinamento de uso do dispositivo mostrando [...] da maneira correta irá trazer \\
benefícios em relação a gastos diários e gestão de dados".
\end{tabular}

Fonte. Os autores (2018) 
Com a disseminação da tecnologia da informática e a produção de computadores velozes e baratos possibilitam uma evolução significativa nos últimos anos no setor rural. Esta nova realidade faz com que o produtor rural esteja mais próximo dos sistemas de informação.

Araújo (2003) ressalta um problema que é a dificuldade de suporte para o uso específico de softwares destinados ao setor agrícola, existe também a falta de softwares adequados às necessidades agrícolas e que muitos produtores têm pouca escolaridade e idade média avançada, o que dificultaria a informatização do agronegócio.

Outra pergunta foi "De acordo com o surgimento das tecnologias de informações no setor do agronegócio, você acha necessário adotar tais inovações?”. As respostas estão no Quadro 14.

\section{Quadro 14: Necessário adotar inovações}

\begin{tabular}{|c|c|}
\hline E1 & $\begin{array}{c}\text { "[...] acho importantíssimas todas as inovações, eu acho que ajuda a gente trabalhar } \\
\text { melhor, controlar melhor [...] precisa de informação, precisa de mais investimento em } \\
\text { questão de formação de pessoas [...]". }\end{array}$ \\
\hline E2 & $\begin{array}{r}\text { "Toda tecnologia que venha a melhorar a produtividade e a quantidade de produto e } \\
\text { produção. [...] eu acho que tem que adotar sim". }\end{array}$ \\
\hline
\end{tabular}

Fonte. Os autores (2018)

Segundo Vieira et al. (2011), "a necessidade de adotar decisões em nível crítico de administração faz com que as empresas do Agronegócio tenham que processar grande quantidade de dados, tornando fundamental o investimento em Tecnologia da Informação."

De modo geral notou-se nas respostas dos entrevistados que as ferramentas de tecnologia podem ajudar o produtor e/ou gestor nas tomadas de decisões em todos os setores do agronegócio; sejam simples consultas ou cotações de commodities agrícolas, até contabilidade da propriedade e utilização de máquinas de precisão. Para a agricultura familiar, a utilização das tecnologias de informações no processo produtivo torna-se um diferencial competitivo por fundamentar a qualidade do produto, dentre outras coisas.

No Quadro 15 destaca-se a seguinte pergunta: "Conhece a estrutura de custos para implantar uma ferramenta de gestão?", diante das respostas, observou-se que os mesmos têm a consciência da importância de se implantar, porém, não possuem conhecimento sobre valores.

\section{Quadro 15: Custos.}

\begin{tabular}{|c|c|}
\hline E1 & “[... não conheço $[\ldots]$ acho que precisaria conhecer $[\ldots]$ ”. \\
\hline E2 & “[...] tenho uma vaga ideia dos valores $[\ldots]$ ”. \\
\hline
\end{tabular}

Fonte: Os autores (2018).

Para Giurliani (1999), o uso de tecnologias de informação carrega consigo custos "invisíveis", que são aqueles pertinentes aos gastos com usuário final, como suporte, treinamento informais, perda de tempo em atividades extremamente elaboradas, custos decorrentes da perda de produtividade, devido à indisponibilidade da informação, entre outros. $\mathrm{O}$ autor ainda destaca que os custos "facilmente" mensuráveis seriam aqueles relacionados à compra de hardware e software, equipamentos, suporte, taxas de comunicação, etc.

Pela análise das entrevistas dos principais gestores da propriedade, pode-se chegar a algumas conclusões. Primeiramente, ficou muito claro de que a propriedade e a forma de gestão da propriedade é de agricultura familiar. Os entrevistados possuem graus de parentesco 
próximos e possuem larga experiência na gestão do negócio em questão. Ficou caracterizado que o processamento de informações dentro da propriedade ainda é feito de forma rudimentar, com pouca utilização de tecnologias de informação e comunicação. O método mais comum utilizado na propriedade é de tentativa e erro e conta com a experiência dos trabalhadores para certas atividades.

É bem aceito pelos produtores de que a tecnologia da informação pode auxiliar nos processos decisórios da empresa e de que estas podem permitir ganhos de produtividade. Porém, quando se fala em acesso e implementação de tais tecnologias na propriedade, encontrase algumas divergências.

Ambos os entrevistados afirmaram que o acesso a tecnologia é difícil. Sabe-se que existem tecnologias disponíveis no mercado, mas não foi detectado grandes esforços para que os mesmos tenham acesso a tais tecnologias. Infere-se então que a busca por tecnologia por parte dos produtores é que pode representar os gargalos para o acesso. Seria necessário primeiramente fazer com que os produtores tivessem acesso a informação, estreitamento no relacionamento com entidades públicas tais como universidades e centros de pesquisa, e órgãos de fomento e financiamento para que o acesso à tecnologia seja facilitado.

É conhecimento de todos que existem grandes programas voltados para a inovação e para a agricultura familiar. O que pode estar acontecendo é que esses programas podem não estar atingindo seu público de forma eficaz, já que os autores alegaram tais dificuldades.

\section{CONCLUSÃO}

Nos últimos anos a tecnologia da informação vem se difundindo no meio rural, e verifica-se que ela pode contribuir positivamente nos aspectos econômicos e ambientais. A tecnologia poderá auxiliar para facilitar a gerência dos novos sistemas produtivos, agilizar o processo de tomada de decisão, controle de custos e produção, permitindo assim, um planejamento melhor das atividades agropecuárias, em busca da otimização com a aplicação dos conceitos embutidos nesses sistemas.

Porém, não basta apenas aplicar a tecnologia a métodos manuais, é necessário mudar a concepção dos processos a partir de sua informatização. Tem-se a necessidade de alterar também a percepção dos produtores, técnicos e trabalhadores, inserindo neles o conceito da importância da coleta da informação de maneira correta.

Sendo assim, o presente estudo buscou compreender as necessidades e dificuldades dos produtores em relação às tecnologias de informação no processo de produção de uma pequena propriedade rural do ramo leiteiro em Rondonópolis-MT. Compreendeu-se como a tecnologia da informação pode influenciar no gerenciamento dos processos de produção e e foi identificada as dificuldades em adotar uma tecnologia de informação no processo de produção.

Buscou-se na literatura referências sobre os principais temas envolvidos desta pesquisa: tecnologia de informação, agronegócio e agricultura familiar. Nessa busca utilizaramse livros e artigos referentes aos temas propostos.

Observou-se na pesquisa que os proprietários possuem um pequeno conhecimento em relação às tecnologias de informação e sabem a importância da mesma para sua propriedade rural. Notou-se que o controle de gastos e de produção ainda é manual e feito de forma parcial, sem o auxílio de nenhuma ferramenta para facilitar e agilizar o processo.

No que se refere às necessidades em adotar uma tecnologia nos processos de produção e de custo, foi observado que se tem a necessidade de um mecanismo que os ajudem durante os processos. Mas ainda existem algumas dificuldades em adotar tais tecnologias como: mão de obra escassa, falta de informação e treinamento, falta de recursos financeiros, pois o 
investimento é alto, entre outros pontos. Outra dificuldade que se observou durante a pesquisa é a dificuldade de adquirir o investimento do Governo para o pequeno produtor, pois existe certa burocracia e na maioria das vezes o produtor deixa de investir na sua propriedade por falta de recursos financeiros.

Em relação a compreender como a tecnologia de informação pode influenciar, nota-se que os proprietários possuem conhecimento que as inovações podem contribuir e melhorar a produção e o bem-estar, mas por conta das dificuldades de investimentos financeiros e por falta de mão de obra capacitada, optam por não adotar as tecnologias disponíveis.

Conclui-se, portanto, que os proprietários alegam ter dificuldades para se ter acesso a tecnologia, que podem ser reflexo de falta de divulgação de informação por parte dos órgãos fomentadores de agricultura familiar, já que é sabido que existem ótimas entidades e programas que fomentam a produtividade da agricultura familiar.

Quanto às limitações no decorrer deste trabalho, os pesquisadores encontraram dificuldades em realizar as entrevistas com mais propriedades que possuem o mesmo ramo de atividade e mesmo tamanho, a fim de configurar melhor os proprietários familiares da região. O estudo também foi limitado em analisar apenas a região da cidade de Rondonópolis/MT.

Sugere-se como estudos futuros, aplicar esta pesquisa em outras pequenas propriedades voltadas a agricultura familiar, pois, é importante comparar umas com as outras, para ver a percepção de outros produtores em relação às tecnologias de informação. Recomenda-se analisar também, as mudanças ocorridas dentro da propriedade rural dentro do contexto tecnológico, tais como se adotaram ferramentas tecnológicas e se houve melhora na produção e no controle de gastos.

\section{REFERÊNCIAS}

ABRAMOVAY, Ricardo. Paradigmas do Capitalismo Agrário em questão. São Paulo. Anpocs, Unicamp, Hucitec, 1992. "Uma nova extensão para a agricultura familiar". In: Seminário Nacional De Assistência Técnica e Extensão Rural. Brasília, DF, Anais, 1997, p. 29

ANTONIALLI, L.M.; GALAN, V.B. Evolução tecnológica e competitividade de uma pequena empresa rural que atua em pecuária leiteira. Cad. Adm. Rural., v.9, n.1, P.-61-73, 1997.

ASSAD, L.; PANCETTI, A. A silenciosa revolução das TICs na agricultura. ComCiência (UNICAMP), Campinas (SP), v. 110, p. x, 2009. Disponível em: $<$ http://comciencia.scielo.br/scielo.php?script=sci_arttext\&pid=S1519-

$76542009000600005 \& \operatorname{lng}=$ pt\&nrm=iso $>$. Acesso em: 20 jan. 2018.

ARAÚJO. M. J. Fundamentos de Agronegócios. São Paulo: Atlas, 2003.

BARDIN, L. Análise de conteúdo. Lisboa, Portugal; Edições 70, LDA, 2009.

BATALHA, M. O.; BUAINAIN, A. M.; SOUZA FILHO, H. M. Tecnologia de gestão e agricultura familiar. Disponível em: <http://www.sober.org.br/palestra/12/02O122.pdf>. Acesso em: 19 dez. 2017.

BECK, U. A reinvenção da política: rumo a uma teoria da modernização reflexiva. In: GUIDDENS, A.; BECK, U.; LASH, S. Modernização reflexiva. São Paulo: Ed. Unesp, 1995. p. 11-71. 
BELTRÃO, N. E. M. Agricultura orgânica e seu potencial como estratégia de produção. In: SIMPÓSIO NACIONAL SOBRE AS CULTURAS DO INHAME E DO TARO, 2.,2002, João Pessoa. Anais... João Pessoa, 2002, p. 71-94.

BUAINAIN, Antônio Márcio; ROMEIRO, Ademar R.; GUANZIROLI, Carlos Agricultura familiar e o novo mundo rural Sociologias, v. 5, n. 10, jul-dez, 2003, p. 312-347. Universidade Federal do Rio Grande do Sul Porto Alegre.

CALEMAN, S. M. Q. Contratos e coordenação. In: ZYLBERSZTAJN, D.; NEVES, M. F.; COLEMAN, S. M. DE Q. (org). Gestão de sistemas de agronegócios. São Paulo: Atlas, 2015.p 71-92.

CARNEIRO, Maria José. Agricultores familiares e pluriatividade: tipologias e políticas. In: COSTA, L.F.C.; MOREIRA, R.J.; BRUNO, R. (org.). Mundo rural e tempo presente. Rio de Janeiro: Mauad, 1999, p. 325- 344.

CASTELLS, Manuel. A sociedade em rede. São Paulo: Paz e Terra, 1999.

CODAF. Importância da Agricultura Familiar. Disponível em: $\langle$ http://codaf.tupa.unesp.br/agricultura-familiar/a-importancia-da-agricultura-familiar $>$. Acesso em: 20 jan. 2018.

CONCEIÇÃO, A. F. “Quem está online?”: um estudo de caso sobre o uso e apropriação da internet no meio rural de Estrela/RS. 2012. Dissertação (Mestrado em Extensão Rural) Programa de Pós-Graduação em Extensão Rural, Centro de Ciências Rurais, Universidade Federal de Santa Maria, Santa Maria, 2012.

CHAYANOV, Alexander V. La organización de la unidad económica campesina. Buenos Aires: Ediciones Nueva Visión, 1974.

DEPONTI, C. M. As "agruras" da gestão da propriedade rural pela agricultura familiar. REDES: Rev. Des. Regional, Santa Cruz do Sul, v. 19, ed. especial, p. 9-24, 2014.

FAYOL, H. Administração industrial e geral: previsão, organização, comando, coordenação, controle. 10. ed. São Paulo: Atlas, 1989.

FERNANDES, B. M. Questões agrarias, pesquisa e MST. São Paulo: Cortez, 2001.

FERRAZ, Caroline De Oliveira; PINTO, Wender Flávio. TECNOLOGIA DA INFORMAÇÃO PARA A AGROPECUÁRIA: Utilização de ferramentas da tecnologia da informação no apoio a tomada de decisões em pequenas propriedades. Revista Eletrônica Competências Digitais para Agricultura Familiar, Tupã, v. 3, n. 1, p. 38-49, jan./jun. 2016. Disponível em: <http://codaf.tupa.unesp.br:8082/index.php/recodaf/article/view/48>. Acesso em: 23 out. 2017.

FOINA, Paulo Rogério. Tecnologia de Informação: Planejamento e gestão. 2. Ed. São Paulo: Atlas, 2012.

GIURLIANI, S. A difícil arte de fazer contas. Gestão Empresarial, v.1, n. 3, p.7-16, 1999.

GIDDENS, A. As consequências da modernidade. São Paulo: Editora Unesp, 1991.

GIL, Antonio Carlos. Como elaborar projetos de pesquisa. 4. ed. São Paulo: Atlas, 2009. 175 p.

HARANDE, Y. I. Information Services for Rural Community Development in Nigeria. Library Philosophy and Practice (e-journal). Paper 271. Disponível em: 
$<$ https://digitalcommons.unl.edu/cgi/viewcontent.cgi?article=1276\&context=libphilprac $>$. Acesso em: 20 jan. 2018.

HESPANHOL, Rosângela Aparecida de Medeiros. A produção familiar: perspectivas de análise e inserção na microrregião geográfica de Presidente Prudente. Tese (Doutorado em Geografia). Rio Claro, 2000.

LAKATOS, E. M.; MARCONI, M. de A. Fundamentos de metodologia científica. 4. ed. São Paulo: Atlas, 2001.

LIMA, M.E.A.T. Análise do discurso e/ou Análise de conteúdo. Psicologia em Revista. Belo Horizonte, 2003.

LIMA, Jorge Roberto Tavares de; FIGUEIREDO, Marcos Antônio Bezerra. Agricultura familiar e desenvolvimento sustentável. In: LIMA, Jorge Roberto Tavares de; FIGUEIREDO, Marcos Antônio Bezerra (org.). Extensão rural, desafios de novos tempos: agroecologia e sustentabilidade. Recife: Bagaço, 2006. p.57-81.

MARCONI, M. de A. LAKATOS, E. M. Metodologia Científica. $5^{\text {a }}$ ed. São Paulo: Atlas, 2011.

MARION, José Carlos; SEGATTI, Sonia. Sistema de gestão de custos nas pequenas propriedades leiteiras. Custos e Agronegócio on line, [S.L], v. 2, n. 2, p. 2-7, jul./dez. 2006. Disponível em:

http://www.custoseagronegocioonline.com.br/numero2v2/Sistema\%20de\%20custos.pdf >. Acesso em: 23 out. 2017.

MARTÍN-BARBERO, J. La comunicación en las transformaciones del campo cultural. lteridades, no 5, México. 1993.

MAXIMIANO, A.C.A. Teoria Geral da Administração: da revolução urbana à revolução digital. 4. ed. São Paulo: Atlas, 2006.

MEIRA, C. A. A. et al. Agroinformática: Qualidade E Produtividade Na Agricultura. Cadernos de Ciência, Brasília, v. 13, n. 2, p. 175-194, ago. 1996.

MENDES, C. I. C.; BUAINAIN, A. M.; FASIABEN, M. C. R. Acesso ao computador e à internet na agricultura brasileira: uma análise a partir do Censo Agropecuário. In: CONGRESSO DA SOBER - SOCIEDADE BRASILEIRA DE ECONOMIA, ADMINISTRAÇÃO E SOCIOLOGIA RURAL, 51., 2013, Belém. Anais... Brasília: SOBER, 2013. Disponível em: < https://www.embrapa.br/busca-de-publicacoes//publicacao/965674/acesso-ao-computador-e-a-internet-na-agricultura-brasileira-uma-analisea-partir-do-censo-agropecuario>. Acesso em: 13 dez. 2017.

MENDRAS, H. Sociedades Camponesas. Rio de Janeiro: Zahar,1978.

MENDES, Judas Tadeu Grassi; JUNIOR, João Batista Padilha. Agronegócio: Uma abordagem econômica. 3 ed. São Paulo: Pearson Prentice Hall, 2007.

MERGAREJO NETTO, M. A. Agricultura familiar e sua organização. Revista Acta Geográfi ca, ano 2, n. 4, p. 17-30, 2008.

MINAYO, M. C. de S. (Org.). Pesquisa social: teoria método e criatividade. $17^{\mathrm{a}}$ ed. Petrópolis, RJ: Vozes, 1994. 80 p. 
PÁDUA, Elisabete. M. M. de. Metodologia da pesquisa: abordagem teórico-prática. $10^{\mathrm{a}}$ ed. rev. e atual. Campinas, SP: Papirus, 2004.

ROSA COUTO, S.L. Agricultura familiar e desenvolvimento local sustentável. $37^{\circ}$ Congresso Brasileiro de Economia e Sociologia Rural - SOBER, Foz do Iguaçu, 1999.

ROSSINI, Alessandro Marco; PALMISANO, Ângelo. Administração de Sistemas de informação e a gestão do conhecimento. - São Paulo: Cengage Learning, 2008.

SANTOS, G.J., MARION, J.C. e SEGATTI, Sonia. Administração de Custos na Agropecuária. 3. ed. São Paulo: Atlas, 2002.

SCHWARTZ, C. A recepção das tecnologias de informação e comunicação entre os agricultores familiares de Santa Maria, Rio Grande do Sul. 2007. Dissertação (Mestrado em Extensão Rural) - Programa de Pós-Graduação em Extensão Rural, Universidade Federal de Santa Maria, Santa Maria, 2007.

SCHNEIDER, S.; NIEDERLE, P. A. Agricultura familiar e teoria social: a diversidade das formas familiares de produção na agricultura. Savanas: desafios e estratégias para o equilíbrio entre sociedade, agronegócio e recursos naturais. Planaltina, DF: Embrapa Cerrados, p. 2008. 989-1014, Disponível em: <http://simposio.cpac.embrapa.br/simposio/projeto/palestras/capitulo_32.pdf>. Acesso em: 19 jan 2018.

SIDERSKY, P. Sobre a especificidade do pequeno produtor: introdução ao debate sobre a unidade econômica camponesa. Olinda, 1990.

SILVA, M. G. A apropriação das TICS por extensionistas e agricultores familiares: possibilidades para o desenvolvimento rural. Tese (Doutorado em Extensão Rural) - Programa de Pós-Graduação em Extensão Rural, Universidade Federal de Santa Maria, Santa Maria, 2014. Disponível em: < http://repositorio.ufsm.br/handle/1/3810>. Acesso em: 2 dez. 2017.

OLIVEIRA, D.C., Análise de Conteúdo TemáticoCategorial: Uma proposta de sistematização. Rev. Enferm. UERJ, Rio de Janeiro, 2008 out/ dez; 16(4):569-76.

OLIVEIRA, A. F. S.; KHAN, A. S.; LIMA, P. V.; SILVA, L. M. R. A Sustentabilidade da agricultura orgânica familiar dos produtores associados à APOI (Associação dos Produtores Orgânicos da Ibiapaba-CE). In: SOCIEDADE BRASILEIRA DE ECONOMIA, ADMINISTRAÇÃO E SOCIOLOGIA RURAL, 16., 2008, Rio Branco. Anais... Amazônia, mudanças globais e agronegócio: o desenvolvimento em questão. Brasília: SOBER, 2008, v. 1, p. $1-20$.

VALLE, Francisco, (1987) - Manual da contabilidade agrária: a produção agrária, a administração da empresa agrária, a contabilidade agrária, 2 ed. São Paulo: Atlas.

VERGARA, Sylvia Constant. Projetos e relatórios de pesquisa em administração. 14. ed. São Paulo: Atlas, 2013.

VIEIRA, F. C.; BACCILI, V. C.C. L.; DELFINO, S. R. Aplicabilidade da tecnologia da informação no agronegócio. RETEC, Ourinhos, v. 4, n. 1, p. 39-52, jan./jun., 2011.

YIN, Robert K. Estudo de caso: planejamento e métodos. 4. ed. - Porto Alegre: Bookman, 2010 . 
WANDERLEY, Maria de Nazareth Baudel. Raízes Históricas do Campesinato Brasileiro. In: TEDESCO, João Carlos (org.). Agricultura Familiar Realidades e Perspectivas. 2a. ed. Passo Fundo: EDIUPF, 1999. Cap. 1, p. 21-55.

WOORTMANN, Klaas. Com Parente não se Neguceia. O campesinato como ordem moral. Anuário Antropológico/87. Edições Tempo Brasileiro. Brasília, 1990. 